\title{
Demiryolu Bakım İşlerinde Matris Yöntemi Kullanılarak Risklerin Olası Etkilerinin Belirlenmesi
}

\begin{abstract}
Kemal URAY1
Özet

Son yıllarda Türkiye'deki demiryolu yatırımları incelendiğinde gelecekte demiryolu ulaşımının daha önemli bir ulaşım modu olacağı görülmektedir. Hatlardaki trafik yoğunluğu ve iyileştirmelere paralel olarak artan hızlarla birlikte demiryolu işletmeciliğinde risklerde de artışlar olacaktır. Tren sefer sayısındaki artış ve yüksek işletme hızları demiryolu hattının bozulmasını hızlandıracak, bunun sonucunda bakım ve yenileme çalışmalarının sayısı artacaktır. Bu bakım ve yenileme çalışmaları işletmenin kesintiye uğramasına sebep olacaktır. Gerçekleștirilen bakım çalıșmaları sırasında hattaki çalışanların güvenliğinin sağlanması için risk analizlerinin yapılması gerekliliği önemli bir konu olarak değerlendirilmelidir. Bu çalışmada, demiryolu bakım müdürlüklerinde yapılan bakım ve iyileştirme faaliyetlerinde meydana gelebilecek risklerin olası etkileri L matris yöntemi kullanılarak matematiksel ifadelere dönüștürülmüș ve her bir iș bölümünün risk puanı hesaplanmıștır. Çalıșmanın amacı örnek olarak seçilen bakım müdürlüğünde, risk tespitlerinin yapılarak risklerin azaltılması ve ortadan kaldırılması için ilgili paydaşlara gerekli önerilerin sunulmasıdır.
\end{abstract}

\section{Determination of Possible Effects of Risks Using Matrix Method in Railway Maintenance Works}

\begin{abstract}
When railway investments in Turkey are examined in recent years, it is seen that railway transportation will be a more important mode of transportation in the future. In parallel with the traffic density and improvements in the lines, the risks in the railway operation with the increasing speeds will be rise. The increase in the number of train services and high operating speeds will accelerate the deterioration of the railway line, as a result of which the number of maintenance and renewal works will increase. These maintenance and renovation works will cause interruption of the business. The necessity of conducting risk analyzes in order to ensure the safety of the employees on the line during the maintenance works
\end{abstract}

${ }^{1}$ TCDD Bakım Dairesi Bașkanlığı, Afyon 7. Bölge Müdürlüğü, 73 Demiryolu Bakım Müdürlüğü, Konya e-posta/e-mail: kemaluray@tcdd.gov.tr ORCID No: 0000-0003-1973-7865

Bu makaleye atıf yapmak için- To cite this article Uray, K. (2021). Demiryolu Bakım İşlerinde Matris Yöntemi Kullanılarak Risklerin Olası Etkilerinin Belirlenmesi. Afet ve Risk Dergisi, 4(2), 121-134. 
should be considered as an important issue. In this study, the possible effects of the risks that may occur in the maintenance and improvement activities in the railway were transformed into mathematical expressions utilizing the $\mathrm{L}$ matrix method, and the risk score of each work unit was calculated. The study aims to present the necessary suggestions to the relevant stakeholders to bay reduce and eliminate the jeopardy by making risk determinations in the selected maintenance directorate.

Keywords: Maintenance Studies, Railway, L Type Matrix, Risk Analysis

\section{GIRIŞ}

Dünyada ve ülkemizde demiryolu taşımacılığının geçmişi oldukça eskiye dayanmaktadır. İlk olarak 1856 yılında 130 kilometrelik İzmir-Aydın hattının yapımıyla başlayan demiryolu ağımız gün geçtikçe artmış, Cumhuriyet ilan edildikten sonra da "ana yurdu demir ağlarla örmek" hedefine bağlı kalınarak önemli ilerlemeler kaydedilmiştir (Göçener, 2012). Ancak, Marshall Planı dahilinde yapılan yardımlarla ülkemiz, 1950 li yıllarda sadece karayollarına odaklanmıș ülkemizdeki demiryolu yatırımları sekteye uğramıștır. Karayolları, dönemin en önemli modernleşme unsuru olarak görülmüștür. Ülkemizde 1939 yılında karayolu aracı sayısı yaklaşık 10.000 iken, 1960 yılına gelindiğinde bu rakam 100.000' leri bulmuştur (Birinci, 2007). Tüm bu engellemeler ve yönlendirmeler sebebiyle demiryolları o dönemde gözden düşmüş ve gerekli yatırımları alamamıştır.

Diğer taraftan, 2000'li yılların başından itibaren teknolojinin gelişmesi ve küreselleșme ile birlikte demiryolu taşımacılığı tekrar önem kazanmaya başlamıştır. Buna bağlı olarak günümüzde yapımı tamamlanan, devam eden ve yapılması planlanan birçok hızlı tren projesi bulunmaktadır. Ayrıca mevcut hatların modernizasyonu günümüz koşullarına uygun olarak TCDD tarafından yapılmaktadır (Tabak, 2014). TCDD'nin günümüzdeki misyonu; kalite, verimlilik ve yenilik ilkeleri çerçevesinde müşteri tercihine göre emniyetli ve güvenli bir şekilde sürdürülebilir yük ve yolcu taşımacılığı yapmaktır (URL 1). Emniyet, konfor ve sürdürülebilir bir hizmet noktasında hatların sürekli faal olmasından dolayı özellikle hatların bakımlarında ya da yapılan diğer tüm operasyonlarda verilen hizmetlerde iş sağlı̆̆ı ve güvenliği kriterlerini dikkate almak hem işin verimliliği hem de çalışanın sağlı̆̆ ve güvenliği için son derece önemlidir. Demiryollarında hattın inşası tamamlandıktan sonra demiryolu hattı ile ilgili tüm faaliyetler demiryolu bakım müdürlüklerince hat bakım el kitabına uygun olarak yapılmakta veya yaptırılmaktadır. Bu faaliyetler arasında; demiryolu hattında yol altyapısı bakımından meydana gelen aksaklıkların giderilmesi, sinyalizasyon sistemlerinde oluşabilecek arızaların giderilmesi, elektrifikasyon sistemlerinde oluşabilecek aksaklıkların giderilmesi ve herhangi bir afet veya kaza durumunda yolun eski haline getirilmesi demiryolu bakım müdürlüklerince yapılmaktadır. (TCDD HBEK, 2013). Bakım müdürlüklerince yapılan tüm bu operasyon faaliyetleri, TCDD'nin benimsediği ve kurum kültürü haline getirmeyi hedeflediği emniyet yönetim sistemi direktifleri doğrultusunda yapılmaya çalışılmaktadır (Kaya, 2019). TCDD’nin emniyet yönetim sistemi politikası, mevcut emniyet anlayışına ilave olarak $A B$ ülkelerinde ve dünyanın gelişmiş ülkelerinde uygulanan düzenlemeleri de göz önünde bulundurarak sistemi en etkin biçimde uygulamaktır. Emniyetin takibi ve iyileştirilmesi için gelecek hedefleri koyarak, gerekli görülen alanlardaki mevzuatta düzenlemeler yapılarak, uluslararası gelişmiş demiryolları ile bilgi iletişiminin sağlanması, emniyet kültürünün oluşturulması ve tüm kullanıcılarda yaygınlaştırılması amacıyla çeşitli kademelerde demiryolu emniyeti ve risk yönetimi müdürlükleri kurulmuştur (TCDD Ar-ge, 2017).

İşletilen raylı sistemlerde yolcu ve sistem güvenliğinin arttırılması amaçlı risklerin azaltılmasında uygulanabilecek yöntem ve süreçlerin incelendiği çalışmalar yapılmıştır (Gündoğdu, 2018). Demiryolu taşımacılığı, toplu taşıma sistemleri içerisinde en güvenilir ve çevreci taşıma sistemidir. Ancak sistemdeki insan faktörü etkisini azaltmak sistemi daha güvenli hale getirecektir. Bu amaçla çeşitli otomasyon ve yazılım sistemlerinin kullanılmasına yönelik 
çalışmalar yapılmıştır (Sarıgüzel, 2021). Yol bakım onarım çalışmaları esnasında oluşabilecek risk durumları için farklı risk analiz yöntemlerinin kullanılıp karşılaştırmalarının yapıldığı çalışmalarda literatürde yer almaktadır (Gürgenli, 2021). Karayolu ulaştırma sitemi ülkemizde en çok tercih edilen ulaştırma sistemidir. Bu kapsamda günümüzde birçok yerde karayolu yapım çalışmaları devam etmektedir. Yapım aşamasında bu çalışmalar içerisinde birçok riski de barındırmaktadır. İnsan ve çevre sağlığına risk teşkil edebilecek tehlikelerin belirlenip L Tipi (5x5) matris yöntemi kullanılarak risk değerlendirmesi çalışması yapılmıştır (Karatürk, 2021). Risk değerlendirmede matris yöntemi kullanılarak mevcut okul binalarındaki risklerin belirlenmesi ve ne tür tedbirlerin alınması gerektiğine dair çalışmalar yapılmıştır (Bayraktar vd., 2019).

\subsection{Demiryolu Bakım Müdürlüklerinde Yapılan Bakım Çalışmaları}

Demiryollarına son yıllarda yatırımların artmasıyla birlikte demiryolu ulaşımına talep artmış, buna bağlı olarak işletme hızı, sefer sayısı ve taşınan yüklerde de artışlar meydana gelmiştir. İşletme hızları ve taşınan yüklere bağlı olarak demiryolu üst yapısı ve raylarda bozulmalar oluşmakta ve bunun sonucunda önemli bakım ihtiyaçları ortaya çıkmaktadır.

TCDD tarafından yapılan ölçümler yüksek hızlı demiryolu hatlarında Piri Reis ölçüm treni ve krab ile konvansiyonel hatlarda ise Roger 800, Matisa MPV-7 ve krab gibi yol geometrisini ölçen alet ve makinalarla yapılmaktadır (TCDD HBEK, 2013). Ölçümlerden elde edilen sonuçlar ise, birçok otoritenin ortak katılımıyla geliştirilmiş olan "EN:13848-5 Demiryolu Uygulamaları-Yol Geometrisi Kalitesi” standardına göre değerlendirilmektedir. Standarda göre dört temel yol geometrik parametresinin önemine dikkat çekilmektedir. Bunlar; yolun kalite düzeyini belirleyen ve Şekil 1'de gösterilip, Tablo 1' de eşik değerleri verilen parametrelerdir.

Tablo 1. Konvansiyonel hatlar için yol geometrik parametreleri sınır değerleri (EN-13848-5:2017)

\begin{tabular}{|c|c|c|c|c|c|c|}
\hline \multicolumn{7}{|c|}{ Normal Ekartman (mm) } \\
\hline \multirow[t]{2}{*}{$\mathrm{Hiz}$} & \multicolumn{2}{|c|}{ AL (Uyarı) } & \multicolumn{2}{|c|}{ IL (Bakım) } & \multicolumn{2}{|c|}{ IAL (Emniyet) } \\
\hline & Min. & Maks. & Min. & Maks. & Min. & Maks. \\
\hline $\mathrm{V}<80$ & -7 & +25 & -9 & +30 & -11 & +35 \\
\hline $80 \leq \mathrm{V}<120$ & -7 & +25 & -9 & +30 & -11 & +35 \\
\hline $120 \leq \mathrm{V}<160$ & -6 & +25 & -8 & +30 & -10 & +35 \\
\hline \multicolumn{7}{|c|}{ Nivelman (mm) } \\
\hline \multirow[t]{2}{*}{$\mathrm{Hiz}$} & \multicolumn{2}{|c|}{ AL (Uyarı) } & \multicolumn{2}{|c|}{ IL (Bakım) } & \multicolumn{2}{|c|}{ IAL (Emniyet) } \\
\hline & $\begin{array}{c}\text { D1 Dalga } \\
\text { Boyu }\end{array}$ & $\begin{array}{c}\text { D2 Dalga } \\
\text { Boyu }\end{array}$ & $\begin{array}{c}\text { D1 Dalga } \\
\text { Boyu }\end{array}$ & $\begin{array}{c}\text { D2 Dalga } \\
\text { Boyu }\end{array}$ & $\begin{array}{l}\text { D1 Dalga } \\
\text { Boyu }\end{array}$ & $\begin{array}{c}\text { D2 Dalga } \\
\text { Boyu }\end{array}$ \\
\hline $\mathrm{V}<80$ & $-/+12$ & Uygulanmaz & $-/+17$ & Uygulanmaz & $-/+28$ & Uygulanmaz \\
\hline $80 \leq \mathrm{V}<120$ & $-/+10$ & Uygulanmaz & $-/+13$ & Uygulanmaz & $-/+26$ & Uygulanmaz \\
\hline $120 \leq \mathrm{V}<160$ & $-/+8$ & Uygulanmaz & $-/+10$ & Uygulanmaz & $-/+23$ & Uygulanmaz \\
\hline \multicolumn{7}{|c|}{ Dever $(\mathrm{mm})$} \\
\hline \multirow[t]{2}{*}{$\mathrm{Hiz}$} & \multicolumn{2}{|c|}{ AL (Uyarı) } & \multicolumn{2}{|c|}{ IL (Bakım) } & \multicolumn{2}{|c|}{ IAL (Emniyet) } \\
\hline & Min. & Maks. & Min. & Maks. & Min. & Maks. \\
\hline $\mathrm{V}<80$ & -10 & +10 & -13 & +13 & -22 & +22 \\
\hline $80 \leq \mathrm{V}<120$ & -8 & +8 & -11 & +11 & -17 & +17 \\
\hline $120 \leq \mathrm{V}<160$ & -7 & +7 & -9 & +9 & -11 & +11 \\
\hline \multicolumn{7}{|c|}{ Nivelman (mm) } \\
\hline \multirow[t]{2}{*}{$\mathrm{Hiz}$} & \multicolumn{2}{|c|}{ AL (Uyarı) } & \multicolumn{2}{|c|}{ IL (Bakım) } & \multicolumn{2}{|c|}{ IAL (Emniyet) } \\
\hline & $\begin{array}{c}\text { D1 Dalga } \\
\text { Boyu }\end{array}$ & $\begin{array}{c}\text { D2 Dalga } \\
\text { Boyu }\end{array}$ & $\begin{array}{c}\text { D1 Dalga } \\
\text { Boyu }\end{array}$ & $\begin{array}{c}\text { D2 Dalga } \\
\text { Boyu }\end{array}$ & $\begin{array}{c}\text { D1 Dalga } \\
\text { Boyu }\end{array}$ & $\begin{array}{c}\text { D2 Dalga } \\
\text { Boyu }\end{array}$ \\
\hline $\mathrm{V}<80$ & $-/+12$ & Uygulanmaz & $-/+15$ & Uygulanmaz & $-/+22$ & Uygulanmaz \\
\hline $80 \leq \mathrm{V}<120$ & $-/+8$ & Uygulanmaz & $-/+11$ & Uygulanmaz & $-/+17$ & Uygulanmaz \\
\hline $120 \leq \mathrm{V}<160$ & $-/+6$ & Uygulanmaz & $-/+8$ & Uygulanmaz & $-/+14$ & Uygulanmaz \\
\hline
\end{tabular}




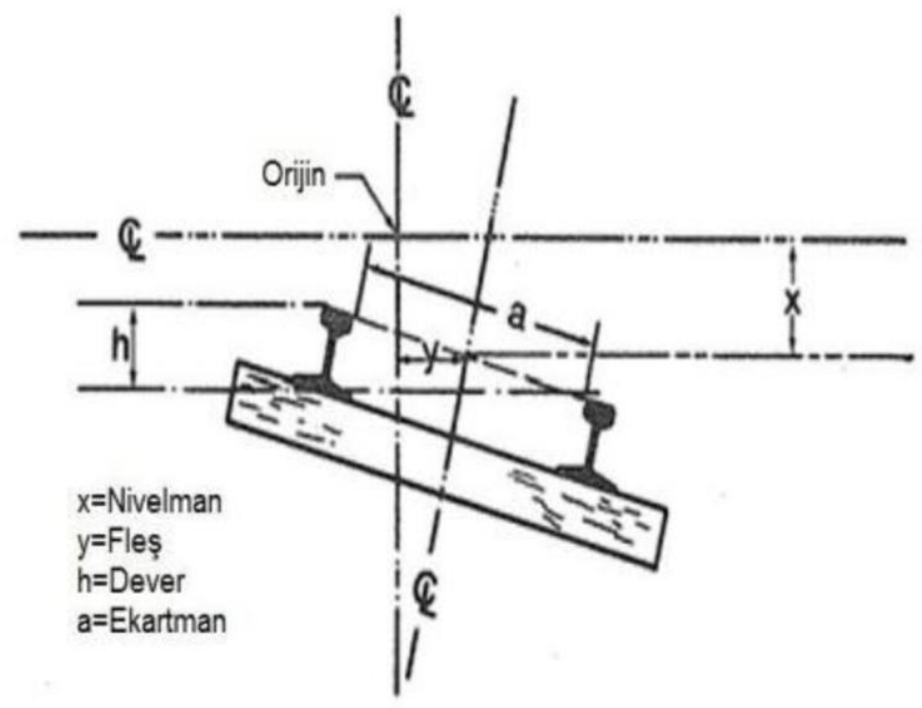

Şekil 1. Demiryolu ölçüm parametreleri

$\mathrm{Bu}$ parametreler kullanılarak ilgili parametrenin limit değerlerine göre değerlendirmeler yapılmakta, buna bağlı olarak da hattın genel kalitesi belirlenerek, bakım ve yol yenileme çalışma programları oluşturulmaktadır (Bilgiç vd., 2017). Şekil 2a, 2b ve 2c' de demiryolu yol geometrisi ölçüm makinaları gösterilmiştir.

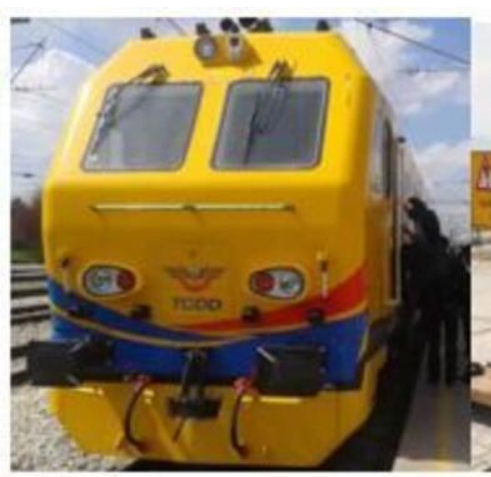

(a)

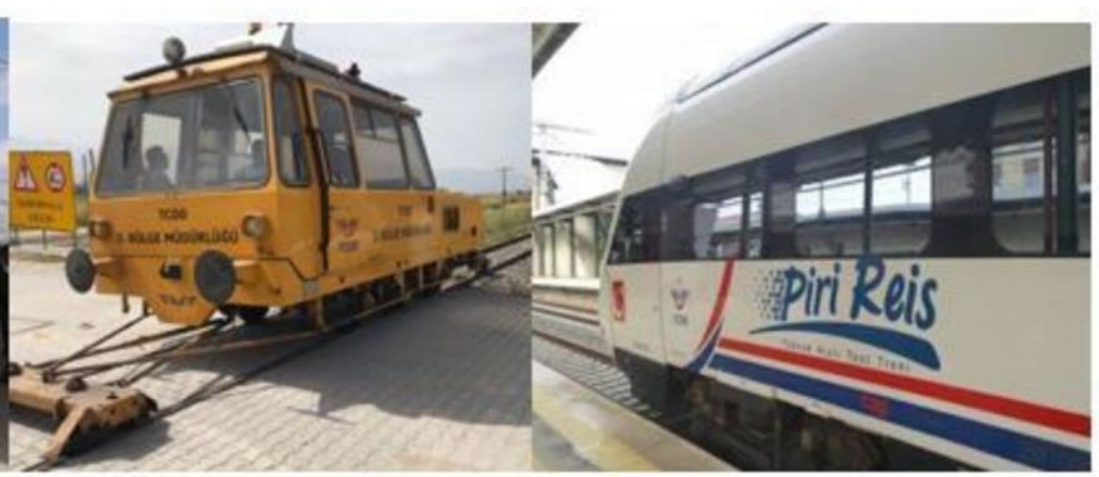

(b)

(c)

Şekil 2. Demiryolu ölçüm makinaları (a: Roger 800, b: MPV-7, c: Piri Reis hızlı demiryolu ölçüm treni)

Yapılan bu aletsel ölçüm ve gözlemsel değerlendirme neticesinde yolda makinalar ve insan eli marifetiyle yapılan bazı çalışmalar aşağıda verilmiştir.

Buna göre; düzgün geometri oluşturmayan ve travers başları açıta bulunan yollarda balastı uygun geometriye getirmek için kullanılan regülatör ve ekonomik ömrünü tamamlayan yol üst yapısının hızlı bir şekilde yenilenmesine olanak sağlayan hızlı demiryolu yenileme aracı Şekil 3a ve 3b' de verilmiştir.

Şekil 4' te yolda oluşabilecek yerel oturmaları, yatay düzlemde meydana gelen kaçmaları ve deverde oluşmuş bozulmaları düzeltmek için kullanılan buraj makinası ve balastlı demiryolu hatlarında balastın bünyesine karışmış ince malzeme ve bitkisel formlardan balastı temizlemek ve balasttan istenen yeterli filtrasyon özelliğini tekrar kazandırmak için yapılan balast eleme çalışması verilmiştir (Koçak, 2014). 
Şekil 5' de demiryolu hattında işçi marifetiyle yapılan bakım çalışması ve sinyalizasyonlu demiryolu hatlarında bulunan sinyalizasyon bakım çalışmaları gösterilmektedir.

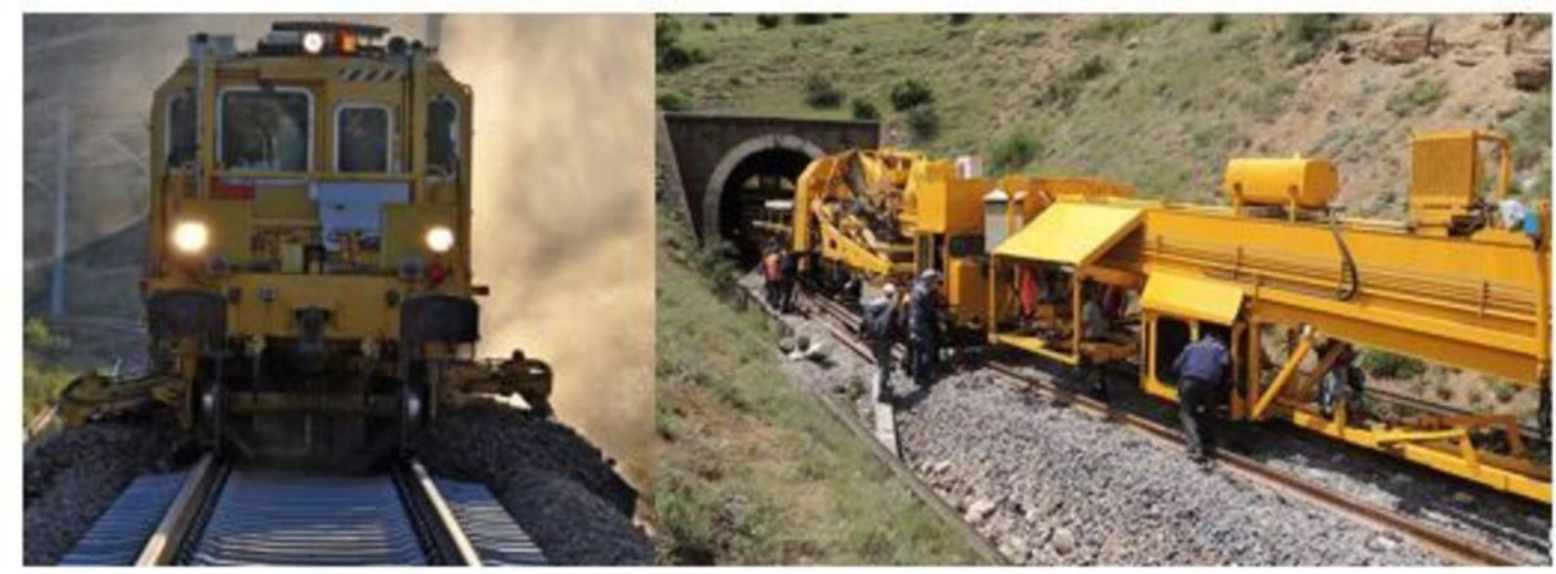

(a)

(b)

Şekil 3. Demiryolu hattında regülatör (a) ve hızlı yol yenileme makinası (b) çalışması

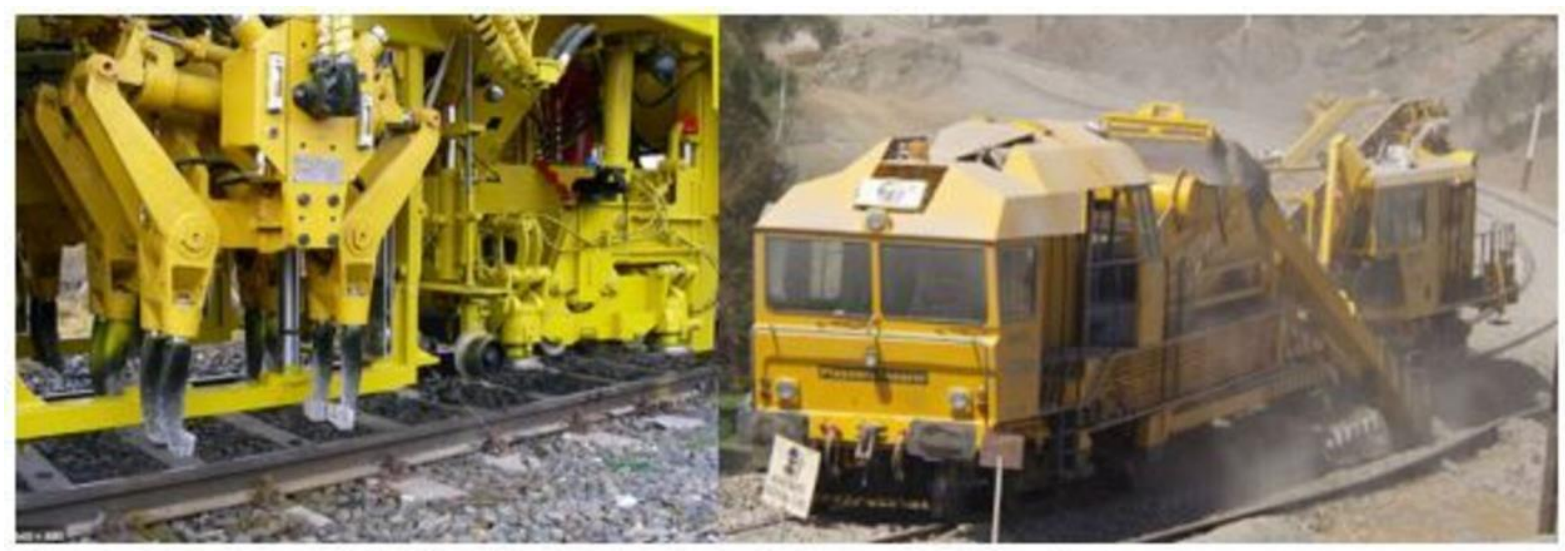

(a)

(b)

Şekil 4. Demiryolu hattında buraj (a) ve balast eleme makinası (b) çalışması

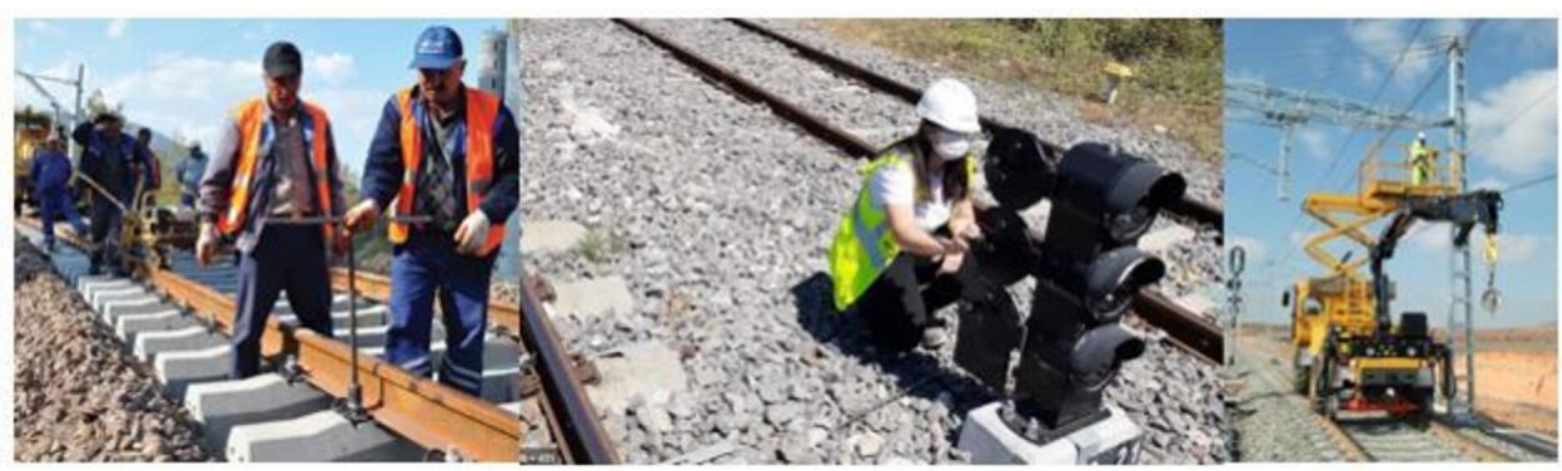

Şekil 5. Demiryolu hattında yapılan diğer bakım çalışmaları 


\section{MATERYAL VE YÖNTEM}

Çalışma kapsamında, Konya 73 Demiryolu Bakım Müdürlüğü'ne bağlı iş yerlerinde yapılan bakım faaliyetlerine göre risk değerlendirilmesi yapılmıştır. Risk değerlendirmesi yapılırken demiryolu bakım işlerinde bu zamana kadar oluşmuş kaza ve kaza öncüleri, aynı zamanda çalışanların yapmış oldukları işlerdeki gözlemlere dayalı iş bilinci yeterlilikleri, emniyet yaklaşımları ve riskin gerçekleşme durumundaki etki boyutu dikkate alınmıştır. İlgili demiryolu bakım müdürlügünün sorumluluk sahası Şekil 6' da işaretli Konya-Afyon arası konvansiyonel tek hatlı demiryoludur. Bu hat üzerinde Konya-İzmir yolcu treni ve muhtelif yük trenleri günlük olarak çalışmaktadır.

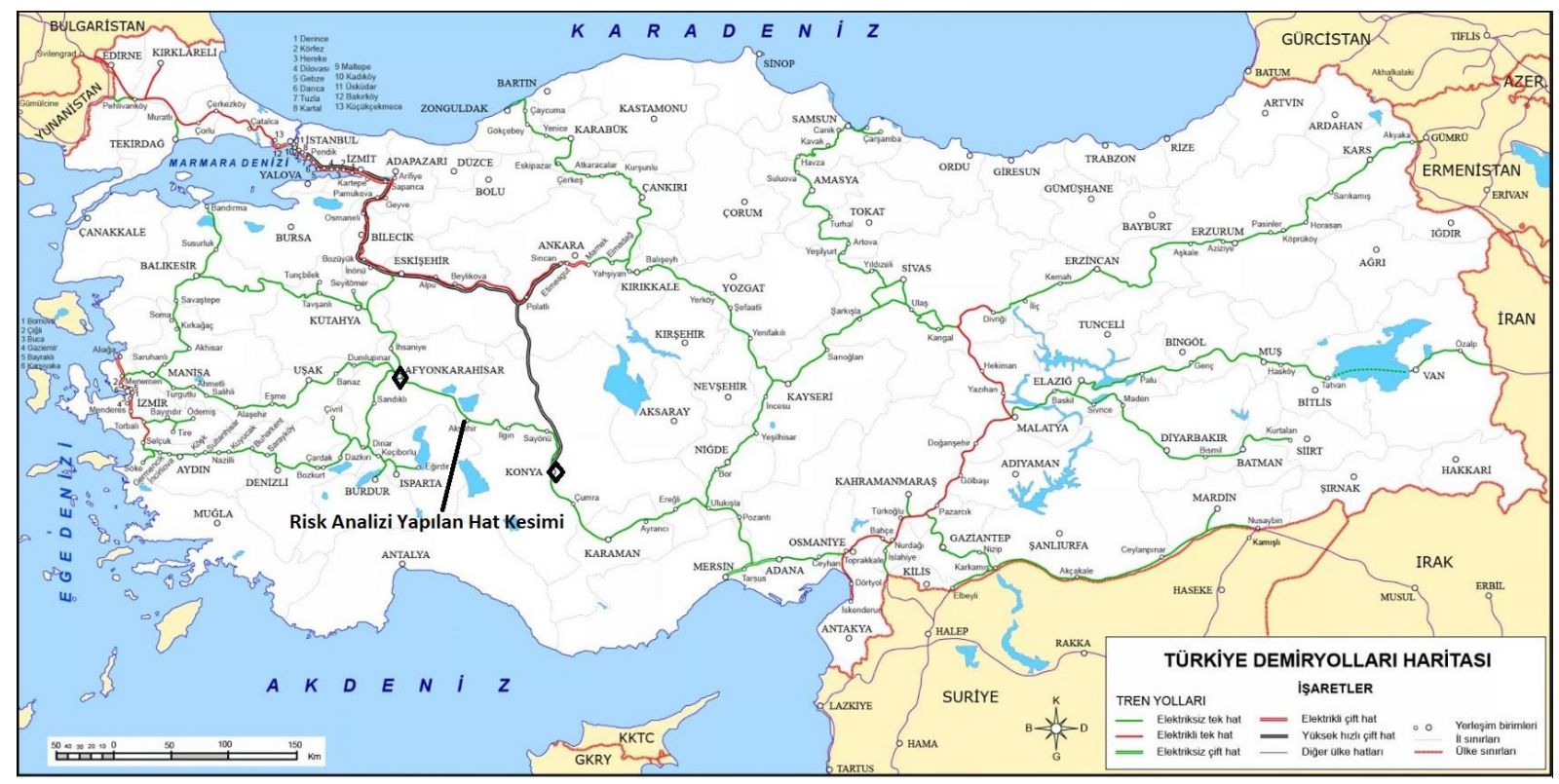

Şekil 6. Çalışma alanının yer bulduru haritası (TCDD, 2012)

Çalışmada, müdürlük demiryolu hattı bölgesinde ve işyeri binalarında oluşabilecek risklerin tespiti, işleri yapan ve yaptıranlarla görüşerek ve gözlemlere dayalı olarak belirlenmiştir. Bu görüşmeler yapılırken demiryolu hattında çalışan kurum elemanları ve yüklenicilerin çalışmaları gözlenmiş, çalışmalara göre listeler yapılarak değerlendirilmiş, bu zamana kadar çalışanların yapmış oldukları demiryolu çalışmalarında ne tür ramak kala olaylarla karşılaştıkları ilgili çalışanlara sorulmuş ve özellikle demiryolu hattında çok uzun yıllar çalışmış ve bu konularda deneyimleri üst seviyede olan yol bakım şeflerinin bilgi ve tecrübelerinden faydalanılmıştır. Diğer yandan iş yerlerinde çalışanlar için fiziki ortam koşulları, ergonomi ve yetersizlikler iş yeri kullanıcıları ile görüşülüp risk değerlendirilmesine tabi tutulmuştur. Ayrıca malzeme stok sahalarında malzeme taşınmasında işçi marifetiyle yapılan işlerde gözlemlenen, bilinçsiz yapılan işlerde oluşabilecek riskler analize dahil edilmiştir. Gözlemlerde kullanılan ekipman ve çalışılan bölgeye göre ( tren trafiği altında, elektrikli ekipman, kesici, delici ekipman vb.) oluşabilecek riskler değerlendirmeye tabi tutulmuştur. Yapılan risk değerlendirmesinde uygulanan bakım çalışmalarına göre riskler en geniş çerçevede ele alınması hedeflenmiş, bu amaçla çalışmalar yapılmıştır. Çalışma sonucunda bakım müdürlüğü sorumluluk sahası ve binalarından elde edilen bilgiler L matris yöntemi kullanılarak sayısallaştırılmıştır.

\subsection{Risk Değerlendirmede Matris Yöntemi}

Çalışmada ortaya konulmaya çalışılan demiryolu bakım müdürlüklerinde risk değerlendirme raporunun hazırlanmasında kullanılan risk değerlendirme yöntemi, formülü ve tabloları ile bunların kullanımına ilişkin bilgiler aşağıda sunulmuştur. 
Risk değerlendirme karar matrisi ABD askeri standardı MIL-STD 882-D olarak da bilinen sistem güvenlik program gereksinimlerini karşılamak maksadıyla geliştirilmiş olup, iki veya daha fazla değișken arasındaki ilişkiyi analiz etmekte kullanılmaktadır. L Tipi Matris (LTM) yönteminde tehlikelerin oluşma olasılığı ile meydana gelme olasılığı arasındaki ilişki analiz edilmektedir. Yöntemin tercih edilmesindeki sebep, kolay ve hızlı oluşu ve bir kişinin dahi yapabilmesidir (Çeliktaş ve Ünlü, 2018).

$$
R=\text { EtkixOlasılık }
$$

Denklem 1' e göre herhangi bir tehdidin oluşmasında etki ve olayın oluşabilme ihtimali risk olarak ifade edilmiştir.

Tablo 2. Risk tablolarının etki sütununda kullanılan değerler (Lafçı ve Öztekin, 2020)

\begin{tabular}{clc}
\hline $\begin{array}{c}\text { Tehdit } \\
\text { Etkisi }\end{array}$ & \multicolumn{1}{c}{ Açıklama } & Şiddet \\
\hline $\mathbf{5}$ & $\begin{array}{l}\text { Ölüm sürekli iş görememezlik, } \\
\text { zararın maliyeti 50.000 tl den fazla }\end{array}$ & 5 \\
\hline $\mathbf{4}$ & $\begin{array}{l}\text { Ciddi yaralanma, uzun süreli tedavi, } \\
\text { meslek hastalığı, zararın maliyeti } \\
\text { 10.000 tl ile 50.000 tl arasında }\end{array}$ & 4 \\
\hline $\mathbf{3}$ & $\begin{array}{l}\text { Hafif yaralanma, tedavi gerektirir, } \\
\text { zararın maliyeti 5000 tl ile 10.000 } \\
\text { tl arasında }\end{array}$ & 3 \\
\hline $\mathbf{2}$ & $\begin{array}{l}\text { İs gücü kaybı yok, ilk yardım } \\
\text { İş saati kaybı yok, ,ilk yardım } \\
\text { gerektiren, zararın maliyeti 1000 tl } \\
\text { den az }\end{array}$ & 1 \\
\hline $\mathbf{1}$
\end{tabular}

Tablo 3. Risk tablolarının tehdidin oluşma ihtimali sütununda kullanılan değerler (Lafçı ve Öztekin, 2020)

\begin{tabular}{cc}
\hline $\begin{array}{c}\text { Tehdidin Oluşma } \\
\text { Olasılığı Değeri }\end{array}$ & Açıklama \\
\hline $\mathbf{5}$ & Çok yüksek \\
\hline $\mathbf{4}$ & Yüksek \\
\hline $\mathbf{3}$ & Orta \\
\hline $\mathbf{2}$ & Küçük \\
\hline $\mathbf{1}$ & Çok küçük \\
\hline
\end{tabular}

Tablo 2 ve Tablo 3’ e göre belirlenen 2 değerin risk formülüne göre çarpımı yapılarak 1 ile 25 arasında risk skorları elde edilmektedir. Buna göre risk değerlendirilmelerinde kullanılacak olan matris formu Tablo 4' te verilmiştir.

Riskin değeri, etki ve riskin oluşma olasılığının çarpılmasıyla elde edilen sonuca göre kabul edilemez, önemli ve düşük olarak sınıflandırılabilmektedir. Buna göre Tablo 5' te elde edilen risk skor aralığına göre uygulanması gereken eylemler verilmiştir. 
Tablo 4. Risk değerlendirme matrisi (Ceylan ve Başhelvacı, 2011)

\begin{tabular}{|c|c|c|c|c|c|}
\hline \multicolumn{6}{|c|}{ RISK DEĞERLENDİRME MATRİII } \\
\hline OLASILIK ŞIDDET & $\begin{array}{l}\text { ÇOK CİDDİ } \\
\text { (5) }\end{array}$ & $\begin{array}{l}\text { CIDDİ } \\
(4)\end{array}$ & $\begin{array}{l}\text { ORTA } \\
\text { (3) }\end{array}$ & $\begin{array}{l}\text { HAFIF } \\
\text { (2) }\end{array}$ & $\begin{array}{l}\text { ÇOK HAFIF } \\
\text { (1) }\end{array}$ \\
\hline $\begin{array}{c}\text { ÇOK YÜUKSEK } \\
\text { (5) }\end{array}$ & $\begin{array}{l}\text { Kabul edilemez } \\
\text { (25) }\end{array}$ & $\begin{array}{c}\text { Kabul edilemez } \\
\text { (20) }\end{array}$ & $\begin{array}{c}\text { Kabul edilemez } \\
\text { (15) }\end{array}$ & $\begin{array}{c}\text { Önemli } \\
(10)\end{array}$ & $\begin{array}{l}\text { Düşük } \\
\text { (5) }\end{array}$ \\
\hline $\begin{array}{c}\text { YÜKSEK } \\
(4)\end{array}$ & $\begin{array}{c}\text { Kabul edilemez } \\
(20)\end{array}$ & $\begin{array}{c}\text { Kabul edilemez } \\
\text { (16) }\end{array}$ & $\begin{array}{c}\text { Önemli } \\
(12)\end{array}$ & $\begin{array}{c}\text { Önemli } \\
\text { (8) }\end{array}$ & $\begin{array}{l}\text { Düşük } \\
(4)\end{array}$ \\
\hline $\begin{array}{l}\text { ORTA } \\
(3)\end{array}$ & $\begin{array}{l}\text { Kabul edilemez } \\
\text { (15) }\end{array}$ & $\begin{array}{c}\text { Önemli } \\
(12)\end{array}$ & $\begin{array}{l}\text { Önemli } \\
(9)\end{array}$ & $\begin{array}{l}\text { Düşük } \\
(6)\end{array}$ & $\begin{array}{l}\text { Düşük } \\
\text { (3) }\end{array}$ \\
\hline $\begin{array}{c}\text { KÜÇÜK } \\
(2)\end{array}$ & $\begin{array}{l}\text { Önemli } \\
(10)\end{array}$ & $\begin{array}{l}\text { Önemli } \\
(8)\end{array}$ & $\begin{array}{l}\text { Düşük } \\
\text { (6) }\end{array}$ & $\begin{array}{l}\text { Düşük } \\
(4)\end{array}$ & $\begin{array}{l}\text { Düşük } \\
(2)\end{array}$ \\
\hline $\begin{array}{c}\text { ÇOK KÜÇÜK } \\
\text { (1) }\end{array}$ & $\begin{array}{l}\text { Düşük } \\
\text { (5) }\end{array}$ & $\begin{array}{l}\text { Düşük } \\
\text { (4) }\end{array}$ & $\begin{array}{l}\text { Düşük } \\
\text { (3) }\end{array}$ & $\begin{array}{c}\text { Düşük } \\
(2)\end{array}$ & $\begin{array}{l}\text { Düşük } \\
\text { (1) }\end{array}$ \\
\hline
\end{tabular}

Tablo 5. Risk skoru aralı̆̆ına göre yapılması gereken aktiviteler

\begin{tabular}{|c|c|c|}
\hline RİSK SKORU & SONUÇ & AKTIVIITE \\
\hline Çok Yüksek & $\begin{array}{c}\text { Kabul Edilmez Risk } \\
(15-25)\end{array}$ & $\begin{array}{l}\text { Belirlenen risk kabul edilebilir bir } \\
\text { seviyeye düşürülünceye kadar iş } \\
\text { başlatılmamalı, eğer devam eden bir } \\
\text { faaliyet varsa derhal durdurulmalıdır. } \\
\text { Alınan önlemlere rağmen riski düşürmek } \\
\text { mümkün olmuyorsa, çalışma } \\
\text { engellenmelidir. }\end{array}$ \\
\hline Orta & $\begin{array}{c}\text { Önemli Risk } \\
(8-12)\end{array}$ & $\begin{array}{l}\text { Belirnen risk azalıncaya kadar iş } \\
\text { başlatılmamalı , eğer devam eden bir } \\
\text { faaliyet varsa derhal durdurulmalıdır. Risk } \\
\text { işin devam etmesi ile ilgiliyse acil önlem } \\
\text { alınmalı ve bu önlemler sonucunda } \\
\text { faaliyetin devamına karar verilmelidir. }\end{array}$ \\
\hline Düşük & $\begin{array}{l}\text { Düşük Risk } \\
(1-6)\end{array}$ & $\begin{array}{l}\text { İlave önlemlerin alınması gerekmeyebilir. } \\
\text { Ancak mevcut kontroller sürdürülmeli ve } \\
\text { bu kontrollerin sürdürüldüğ̈ } \\
\text { denetlenmelidir. }\end{array}$ \\
\hline
\end{tabular}

\section{BULGULAR VE SONUÇLAR}

Bu bölümde Konya 73 Demiryolu Bakım Müdürlüğü ve bağlı işyeri binalarında, Konya 73 Demiryolu Bakım Müdürlügü sorumluluk bölgesinde yapılan çalışmalara ait risk değerlendirme bulguları sunulacaktır. Çalışmada Bakım Müdürlügü için bulunan "çok yüksek" risk seviyesinin üzerinde durulmuş ve bu seviyede olan riskler için daha fazla dikkatli olunmasının altı çizilmiştir. Buna göre Konya 73 Demiryolu Bakım Müdürlüğü Risk Değerlendirme Çalışması kapsamında risk analizi kontrol listeleri, demiryolu yol bakım onarım çalışmaları, işyeri ve ortamında yapılan çalışmalar, elektrifikasyon çalışmaları ve sinyalizasyon çalışmaları için sırasıyla Tablo 6-9'da verilmiştir. 
Tablo 6. Demiryolu yol bakım onarım çalışmaları risk analizi kontrol listesi

\begin{tabular}{|c|c|c|c|c|}
\hline No & Risk & Olasılık & Şiddet & $\begin{array}{l}\text { Risk } \\
\text { Skoru }\end{array}$ \\
\hline 1 & $\begin{array}{l}\text { İş makinelerinde hareketli ve yüksek devirli parçalarda parça } \\
\text { kopması riski }\end{array}$ & 5 & 5 & 25 \\
\hline 2 & İș makinelerinde demiryolu trafiğine bağlı çarpıșma riski & 5 & 5 & 25 \\
\hline 3 & İș makinelerinde gürültülü ortam koșullarına bağlı riskler & 4 & 5 & 20 \\
\hline 4 & İș makinelerinde așırı titreșimli ortam & 4 & 4 & 16 \\
\hline 5 & Yüksek basınçlı hidrolik ve pnömatik sistemler & 4 & 4 & 16 \\
\hline 6 & Malzeme sökme takma sırasında parça düşmesi riski & 4 & 4 & 16 \\
\hline 7 & Bakım onarım ve kaynak ișleri sırasında sıcak yüzey teması & 4 & 4 & 16 \\
\hline 8 & Bakım onarım esnasında trafiğe bağlı kaza riski & 4 & 4 & 16 \\
\hline 9 & Kaynak çalıșmalarına bağlı yangın ve yaralanma riski & 4 & 4 & 16 \\
\hline 10 & $\begin{array}{l}\text { Elektrik kaynağı yapımı sırasında elektrik kaçağına bağlı elektrik } \\
\text { çarpması riski }\end{array}$ & 3 & 5 & 15 \\
\hline 11 & Yol tamiratları sırasında taș firlaması sonucunda yaralanma riski & 3 & 4 & 12 \\
\hline 12 & $\begin{array}{l}\text { İş makinaları ile çalışmalar sırasında kaygan ve engelli zemine bağlı } \\
\text { olarak düşme riski }\end{array}$ & 4 & 4 & 16 \\
\hline 13 & Oksijen kaynak ekipmanlarına bağlı olarak patlama riski & 3 & 5 & 15 \\
\hline 14 & $\begin{array}{l}\text { İş makinalarında aydınlatma, ikaz ve haberleşme sistem arızalarına } \\
\text { bağlı riskler }\end{array}$ & 3 & 5 & 15 \\
\hline 15 & Vagon çekilmesi ve manevrası esnasında oluşabilecek riskler & 4 & 4 & 16 \\
\hline 16 & $\begin{array}{l}\text { Yetkisiz ve izinsiz kişilerin çalışma alanlarına girmesine bağlı } \\
\text { oluşabilecek riskler }\end{array}$ & 3 & 5 & 15 \\
\hline 17 & Elle yük tașımaya bağlı oluşabilecek riskler & 4 & 4 & 16 \\
\hline 18 & Taşlama esnasında tașın patlamasına bağlı riskler & 4 & 4 & 16 \\
\hline 19 & Taşlama tezgâhında yapılan çalıșmalarda göze çapak kaçması & 4 & 4 & 16 \\
\hline 20 & Vagon üzerinde emniyetsiz çalıșmaya bağlı düșme riskleri & 3 & 4 & 12 \\
\hline 21 & $\begin{array}{l}\text { Vagon üzerinde emniyetsiz çalışmaya bağlı el kesilmesi ve } \\
\text { yaralanma riski }\end{array}$ & 4 & 5 & 20 \\
\hline 22 & Vagon çarpmasına bağlı yaralanma ve ölüm riski & 4 & 5 & 20 \\
\hline 23 & $\begin{array}{l}\begin{array}{l}\text { Vagonların kapalı alanlara girerken güvenlik önlemlerinin } \\
\text { alınmaması }\end{array} \\
\end{array}$ & 4 & 5 & 20 \\
\hline 24 & Oksi -Asetilen tüpleri ve LPG tüplerine bağlı yangın riski & 3 & 4 & 12 \\
\hline 25 & $\begin{array}{l}\text { Oksi -Asetilen tüpleri ve LPG tüplerinde, tüplerin çıkışında ve } \\
\text { şalomanın girişinde alev geri tepme valfleri olmaması riski }\end{array}$ & 4 & 5 & 20 \\
\hline 26 & $\begin{array}{l}\text { Oksi -Asetilen tüpleri ve LPG tüplerine bağlı dumana maruz kalma } \\
\text { riski }\end{array}$ & 4 & 4 & 16 \\
\hline 27 & Oksi -Asetilen tüpleri ve LPG tüplerinin darbe alması riski & 4 & 5 & 20 \\
\hline 28 & $\begin{array}{l}\text { Oksi -Asetilen tüpleri ve LPG tüplerine bağlı kaynak ışınlarına } \\
\text { maruziyet riski }\end{array}$ & 3 & 3 & 9 \\
\hline
\end{tabular}

Tablo 7. İşyeri ve çalışma ortamı risk analizi kontrol listesi

\begin{tabular}{|l|l|l|l|l|}
\hline No & Risk & Olasılık & Şiddet & $\begin{array}{l}\text { Risk } \\
\text { Skoru }\end{array}$ \\
\hline 1 & $\begin{array}{l}\text { Bakımı yapılmayan elektrikli çay ocağından kaynaklı elektrik } \\
\text { çarpması riski }\end{array}$ & 3 & 5 & 15 \\
\hline 2 & Elektrikle ilgili arızalara yetkisiz kișilerce müdahale & 4 & 5 & 20 \\
\hline 3 & $\begin{array}{l}\text { Elektrikli el aletlerinin kablolarının hasarlı olması, kontrol } \\
\text { edilmemesi }\end{array}$ & 3 & 4 & 12 \\
\hline 4 & İş sağlı̆̆ ve güvenliği eğitimi eksikliği & 3 & 4 & 12 \\
\hline 5 & $\begin{array}{l}\text { Periyodik tetkikler ( Odyometri, Solunum Fonksiyon testi, PA } \\
\text { Akciğer grafilerinin ) çekilmemesi }\end{array}$ & 3 & 5 & 15 \\
\hline 6 & İșyerinde yangın tüpü olmaması & 3 & 5 & 15 \\
\hline
\end{tabular}


Demiryolu Bakım İşlerinde Matris Yöntemi Kullanılarak Risklerin Olası Etkilerinin Belirlenmesi

\begin{tabular}{|l|l|l|l|l|}
\hline 7 & Tüm kapalı alanlarda kaçak akım rölesi olmaması & 3 & 5 & 15 \\
\hline 8 & Uzun süre bilgisayarla çalıșma & 3 & 3 & 9 \\
\hline 9 & Araç şoförleri tarafından hızlı araç kullanma & 3 & 4 & 12 \\
\hline 10 & Malzemelerin uygun şekilde istiflenmemesi ve depolanmaması & 3 & 3 & 9 \\
\hline 11 & Elle 25 Kg geçen malzeme taşınması & 3 & 5 & 15 \\
\hline 12 & Panoların kaçak akım rölesi ve gövde topraklaması olmaması & 4 & 5 & 20 \\
\hline 13 & Yangın söndürme tüplerinin değișimi & 3 & 5 & 15 \\
\hline 14 & Acil durum iletişim bilgileri eksikliği & 5 & 5 & 25 \\
\hline 15 & Psikoteknik etkenlere bağlı riskler & 5 & 5 & 25 \\
\hline 16 & $\begin{array}{l}\text { Ilkyardım çantası eksikliklerine bağlı acil müdahalenin gecikmesi } \\
\text { riski }\end{array}$ & 4 & 4 & 16 \\
\hline 17 & $\begin{array}{l}\text { Masa düzeni, bilgisayar konumu ve sandalyenin uygunsuzluğu bağlı } \\
\text { riskler }\end{array}$ & 4 & 3 & 12 \\
\hline 18 & Ekranlı araçlarla çalıșmaya bağlı riskler & 3 & 3 & 9 \\
\hline 19 & Malzemelerin uygun șekilde istiflenmemesi sonucu yaralanmalar & 3 & 3 & 9 \\
\hline 20 & Uygun olmaya termal konfor şartları & 3 & 2 & 6 \\
\hline
\end{tabular}

Tablo 8. Elektrifikasyon çalışmaları risk analizi kontrol listesi

\begin{tabular}{|l|l|l|l|l|}
\hline No & Risk & Olasılık & Şiddet & $\begin{array}{l}\text { Risk } \\
\text { Skoru }\end{array}$ \\
\hline 1 & Eğitim eksikliğine bağlı riskler & 3 & 4 & 12 \\
\hline 2 & İșe uygun personelin seçilmemesi & 2 & 5 & 10 \\
\hline 3 & Yetkisiz şahısların trafo merkezlerine giriș çıkıșları & 5 & 5 & 25 \\
\hline 4 & İletișim ve koordinasyon eksikliği & 5 & 5 & 25 \\
\hline 5 & İklim ve hava koșullarına bağlı olușabilecek riskler & 4 & 5 & 20 \\
\hline 6 & Çalıșma esnasında uygun olmayan saha aydınlatması & 3 & 5 & 15 \\
\hline 7 & Terör ve sabotaj & 2 & 5 & 10 \\
\hline 8 & $\begin{array}{l}\text { Elektrifikasyon sistemi kanal kapaklarının açık kalması durumuna } \\
\text { bağlı yaralanmalar }\end{array}$ & 3 & 4 & 12 \\
\hline 9 & AC ve DC panolarda olușabilecek riskler & & & \\
\hline 10 & Manevra sırasında olușabilecek hatalı ișlemler & 5 & 5 & 25 \\
\hline 11 & Manevra sırasında kesicinin uzaktan kumanda olmaması & 5 & 5 & 25 \\
\hline 12 & Elektrifikasyon sisteminde șalta izinsiz veya bilinçsiz giriș & 5 & 5 & 25 \\
\hline 13 & İse uygun olmayan iș eldiveni ve ayakkabısı kullanmak & 5 & 5 & 25 \\
\hline 14 & Enerjili bölümlere dokunma & 5 & 5 & 25 \\
\hline
\end{tabular}

Tablo 9. Sinyalizasyon çalışmaları risk analizi kontrol listesi

\begin{tabular}{|c|c|c|c|c|}
\hline No & Risk & Olasilık & Şiddet & $\begin{array}{l}\text { Risk } \\
\text { Skoru }\end{array}$ \\
\hline 1 & $\begin{array}{l}\text { Akü şarj başlığı ve aparatına elle temas neticesinde elektrik } \\
\text { çarpması }\end{array}$ & 4 & 4 & 16 \\
\hline 2 & $\begin{array}{l}\text { Sinyalizasyon sistemi ekipmanlarının elle taşınması esnasında } \\
\text { uzuvlarda oluşacak ağrılar }\end{array}$ & 4 & 3 & 12 \\
\hline 3 & Elektrik panolarının uygunsuzluğu sonucu elektrik çarpması & 3 & 5 & 15 \\
\hline 4 & Tașlama tezgâhı ve spiral kullanımına bağlı olarak tașın patlaması & 4 & 5 & 20 \\
\hline 5 & $\begin{array}{l}\text { Elektrikli el aletlerinin kablolarının hasarlı olması durumuna bağlı } \\
\text { olarak elektrik çarpması }\end{array}$ & 4 & 5 & 20 \\
\hline 6 & $\begin{array}{l}\text { Zeminden emniyetsiz biçimde geçirilmiş elektrik kabloları } \\
\text { neticesinde elektrik çarpması }\end{array}$ & 3 & 5 & 15 \\
\hline 7 & $\begin{array}{l}\text { İșe uygun standartlarda iş ayakkabısı ve eldiveni kullanmayan } \\
\text { çalışanlar }\end{array}$ & 4 & 5 & 20 \\
\hline 8 & $\begin{array}{l}\text { Pano ve trafoların önünde yalıtkan paspas olmaması durumunda } \\
\text { olușabilecek elektrik çarpmaları }\end{array}$ & 4 & 5 & 20 \\
\hline
\end{tabular}




\begin{tabular}{|l|l|l|l|l|}
\hline 9 & $\begin{array}{l}\text { Hemzemin geçitlerde yapılan çalışmalarda gerekli önlemlerin } \\
\text { alınmaması }\end{array}$ & 4 & 5 & 20 \\
\hline 10 & İș sağlığı ve güvenliği eğitimi eksikliğine bağlı riskler & 5 & 5 & 25 \\
\hline 11 & Tüm kapalı alanlarda kaçak akım rölesi olmaması & 3 & 5 & 15 \\
\hline 12 & Elle 25 kg'ı geçen malzeme taşınması & 3 & 3 & 9 \\
\hline 13 & Uygun olmayan aydınlatmaya bağlı çarpma ve düşme & 3 & 3 & 9 \\
\hline 14 & Anti statik KKD bulunmaması & 3 & 4 & 12 \\
\hline
\end{tabular}

Risk skoru belirlemede olasılık ve şiddet sayısal değerlerinin tespiti önemlidir. Olasılık, herhangi bir işle ilgili riskin, başlangıç olayının oluşması ve önlemlerin çalışıp çalışmama durumları dikkate alınarak, kaza olayının oluşma ihtimalini ifade etmektedir. Buna göre yapılan risk değerlendirme çalışması özelinde "Bakımı yapılmayan elektrikli çay ocağından kaynaklı elektrik çarpması riski” olasılığı 3 olarak belirlenmiştir. Aynı şekilde riskin gerçekleşmesi durumunda şahısta oluşturacağ etkinin derecesi risk analizi kontrol listesinde şiddet olarak ifade edilmiştir. Buna göre yapılan risk değerlendirme çalışması özelinde "Bakımı yapılmayan elektrikli çay ocağından kaynaklı elektrik çarpması riski” şiddeti 5 olarak belirlenmiştir.

Tablo 6-9' da verilen risk skorlarına göre demiryolunda yapılan çalışmaların büyük çoğunluğu çok yüksek risk sınıfında yer aldığı görülmüştür. Bu sebeple alınması gereken önlemler personel güvenliği ve makine ekipmanları açısından aşağıda maddeler halinde verilmiştir;

- Yapılan tüm çalışmalarda özellikle çalışanlar tarafından yapılan işin mahiyetine göre uygun baret, ikaz yeleği vb kişisel koruyucu donanımlarının (KKD) kullanılmalıdır.

- Diğer yandan çalışmaların çoğu tren trafiği altında gerçekleştirildiğinden çalışmalar esnasında çalışma alanı ile trafik yönetimi arasındaki koordinasyon uyumlu ve kesintisiz olmalıdir.

- Aynı zamanda çalışmalar esnasında kullanılan makine ve ekipmanların bakımları zamanında ve eksiksiz olarak yapılmalıdır.

- Hat üzerinde çalıșan personele iș sağlığı ve güvenliği açısından gerekli bilgilendirmeler her işe başlamadan önce kısa olarak verilmeli ve yeterli çalışma bilinci sağlanmalıdır.

İşyerleri ve ofis çalışma ortamlarının risk analiz sonuçları Şekil 7'ye göre incelendiğinde çalışma ortamlarında daha çok alansal yetersizlikler ve bilinçsiz çalışmalara bağlı riskler ön plana çıkmaktadır. Yapılan incelemelere göre tüm risklerin \%55'ini çok yüksek riskler, \%40'ını orta riskler ve \%5'lik bir bölümünü ise düşük riskler oluşturmaktadır.

Risk Seviyesi

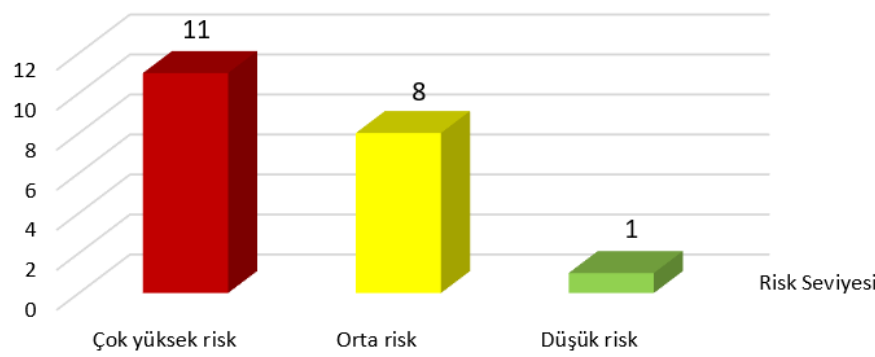

Oransal Dağılım

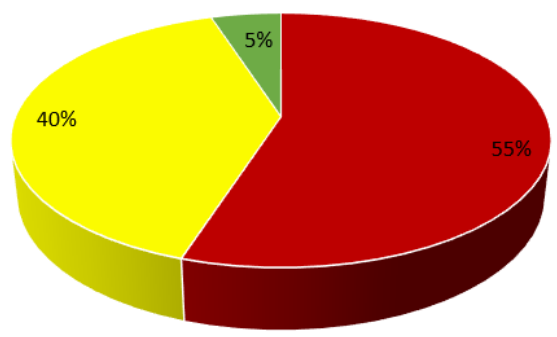

- Çok yüksek risk = Orta risk = Düşük risk

Şekil 7. Demiryolu bakım müdürlüğü çalışma ortamı risk seviyeleri ve oransal dağılımlar 
Yol bakım çalışmaları risk analiz sonuçları Şekil 8' e göre incelendiğinde yol bakım çalışmaları esnasında yapılan işlerin büyük bir bölümünün çok yüksek risk grubuna giren işlerden oluştuğu, sebebinin ise çalışmaların tren trafiği altında, yoğun güç ve iş bilinci gerektiren çalışmalar olması sebebiyle olduğu düşünülmektedir. Buna göre yol bakım çalışmalarında değerlendirmeye tabi tutulan işlerin \%86'sı çok yüksek riskli ve \%14'ü ise orta seviye riskli işlerden oluşmaktadır.

Sinyalizasyon bakım çalışmaları risk analiz sonuçları Şekil 9' e göre değerlendirildiğinde işlerin çoğunun elektrik ile ilgili işler olduğu ve yine tren trafiği altında çalışmaların yapıldığı buna bağlı olarak göz önünde bulundurulan risklere göre \% 79' unun çok yüksek risk barındırdığı, \% 21 ' inin ise orta seviyede risklerin oluşturduğu görülmektedir.

Elektrifikasyon bakım çalışmaları risk analiz sonuçları Şekil 10' a göre değerlendirildiğinde yapılan işlerin tamamı yüksek voltaj elektrik akımı barındıran katener telleri üzerinde olduğu, çalışmaların çok dikkatle yapılması gerektiği, herhangi bir dikkatsizlik durumunda hayati tehlikelerle karşılaşılabilineceği hususunun altı çizilmiştir. Buna göre göz önünde bulundurulan değerlendirmeler ışığında risklerin \%71'inin çok yüksek risk, \%29'unun ise orta sevideki risklerden oluştuğu görülmektedir.

Risk Seviyesi

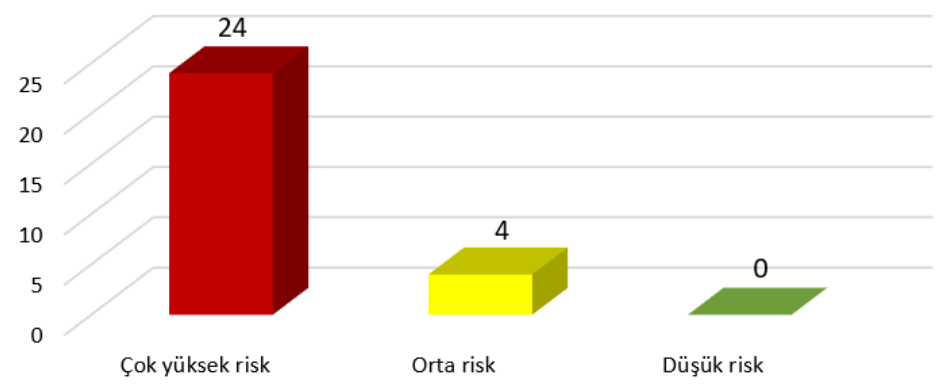

Oransal Dağııım

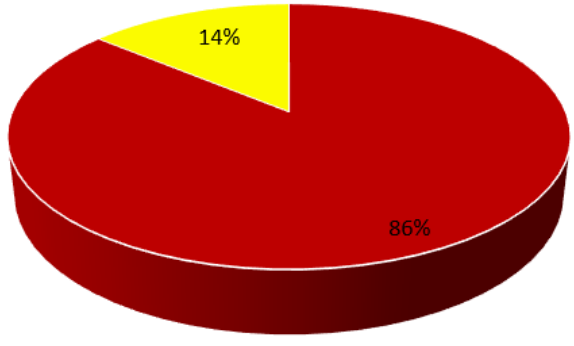

- Çok yüksek risk = Orta risk = Düşük risk

Şekil 8. Demiryolu bakım müdürlüğü yol bakım çalışmaları risk seviyeleri ve oransal dağılımlar

Risk Seviyesi

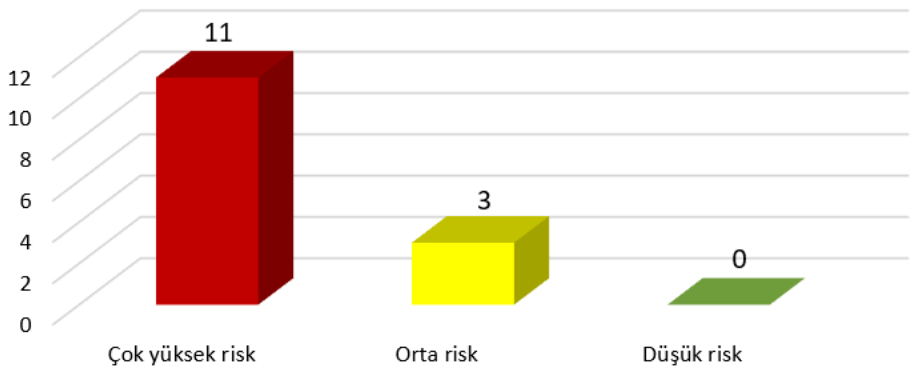

Oransal Dağııım

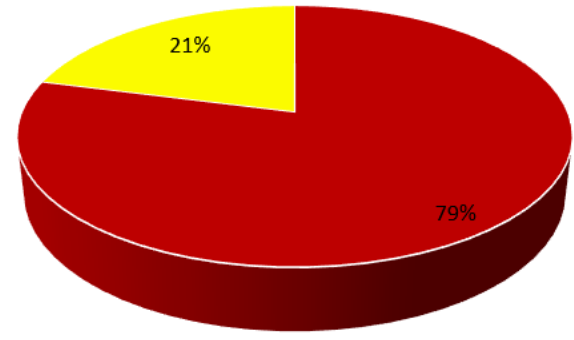

- Çok yüksek risk = Orta risk = Düşük risk

Şekil 9. Sinyalizasyon bakım çalışmaları risk seviyeleri ve oransal dağılımlar 

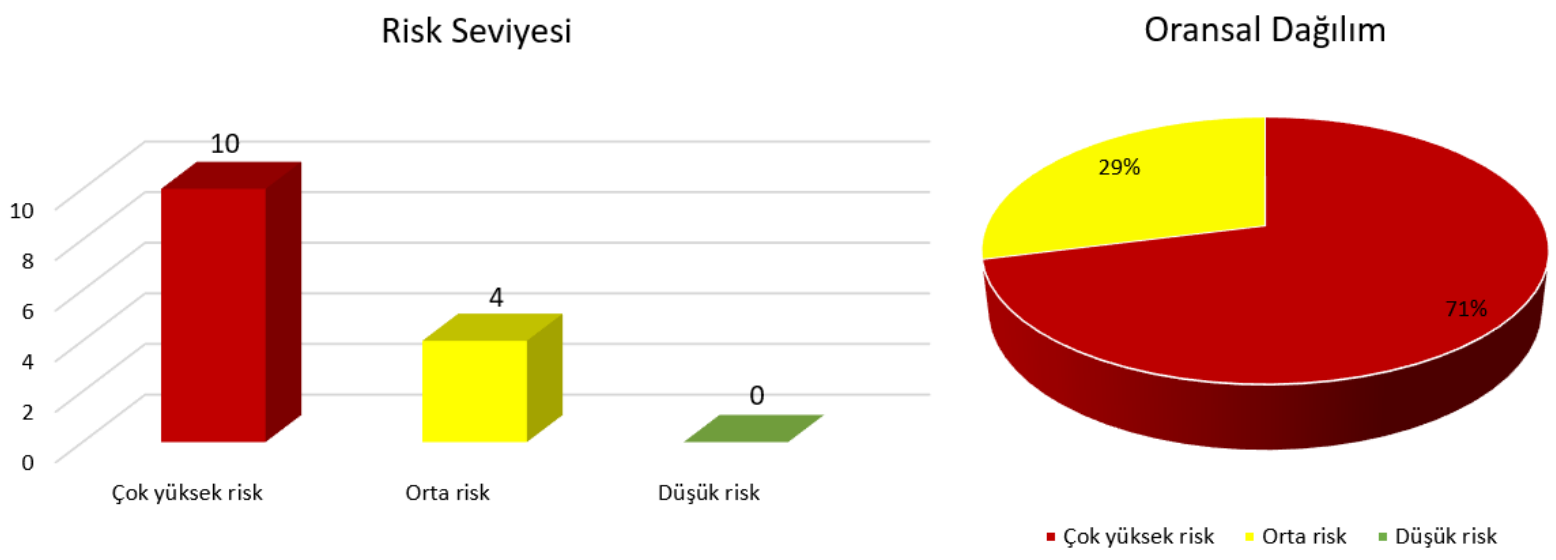

Şekil 10. Elektrifikasyon bakım çalışmaları risk seviyeleri ve oransal dağılımlar

TCDD'nin benimsediği kurumsal emniyet yönetim sistemi faaliyet ve çalışmalarında üst yönetimden destek almaktadır. TCDD'de akademik bilgi düzeyi yüksek çalışanların bulunması, emniyet kurulları ve komitelerinin oluşturulması, demiryolu sisteminin farklı alanlarında çalışan deneyimli demiryolcuların bulunması ve ERTMS gibi gelișmiş demiryolu sistemlerinin kullanılması risklerin berteraf edilmesi noktasında demiryollarının kuvvetli yanlarını oluşturmaktadır. Diğer yandan yerel emniyet kavram ve yaklaşımlarının gelişmiş olması, cezalandırma odaklı soruşturma ve denetim kültürü, mevzuat boşlukları ve neden analizlerinin tam manasıyla yapılmaması TCDD’nin zayıf yönlerini oluşturmaktadır. Çalışma ortamındaki stres ve iş yükleri, yeni gelișen birçok teknoloji ile birlikte ortaya çıkan eğitim gereksinimleri ve yeni gelişen teknolojiler ile birlikte ortaya çıkan iş kaynaklı yeni risk ve tehlikeler ise ilerde gerçekleşebilecek tehditleri oluşturmaktadır. TCDD’nin proaktif bir yaklaşım belirleyerek, tüm sistemlerde oluşabilecek tehlikelerin önüne geçilmesini sağlayacak tehlike bariyerleri geliştirmesi, bu geliştirmeleri yaparken de sürekli gelişim ve ilerleme vizyonuna göre revize etmesi uygun olacaktır.

\section{KAYNAKLAR}

Bayraktar, H., Sahtiyancl, E., ve Kuru, A. (2019). Risk Değerlendirme Matris Yöntemi Kullanarak Okullarda Deprem Kaynaklı Yapısal Olmayan Risklerin Olası Etkilerinin Belirlenmesi. Afet ve Risk Dergisi, 2(2), 128-152.

Bilgiç, Ş., Yalınız, P., ve İça, S., (2017). Demiryollarında Bakım ve Onarım Faaliyetlerinin Yol Geometrisi Kalitesine Etkilerinin Araştırılması: Kütahya- Afyonkarahisar Demiryolu Hattı Örneği, Engineering Sciences (NWSAENS), 12(1):40-45, DOI: 10.12739/NWSA

Birinci, B. (2007). The Marshall Plan In Turkey, A Critıcal Evaluation Of United States' Interests In The Plan And Its Effects On The Republıc. (Yüksek Lisans Tezi, Boğaziçi Üniversitesi, Türkiye).

Ceylan, H., \& Başhelvacı, V. S. (2011). Risk değerlendirme tablosu yöntemi ile risk analizi: Bir uygulama. International Journal of Engineering Research and Development, 3(2), 25-33.

Çeliktaș, B., \& Ünlü, N. (2018). Risk Değerlendirme Karar Matrisi Yöntemi Kullanarak Örnek Bir Risk Değerlendirme Raporunun Oluşturulması. Jass Studies-The Journal of Academic Social Science Studies, Doi number: http://dx. doi. org/10.9761/JASSS7527, (65), 483-504.

Göçener, M. (2012). Demiryollarında İş Sağlığı ve Güvenliği, Erişim Tarihi: 19.06.2021. http://www.isgum.gov.tr/rsm/file/isgdoc/IG12-demiryollarinda isg.pdf 
Gürgenli, M. G. (2021). Yol Yapım Bakım ve Onarım Çalışmalarında Risk Analizi. (Yüksek Lisans Tezi, Sivas Cumhuriyet Üniversitesi, Türkiye).

Gündoğdu, F. (2018). Raylı Sistemlerde Tehlike ve Risk Analizi ile Emniyetin Arttırılması. Eser Müşavirlik Mühendislik A.Ş, Ankara, Türkiye.

Karatürk, B. (2021). İş sağlı̆̆ı ve güvenliğinde risk analizi: Karayolları yapım çalışmalarından bir uygulama (Yüksek Lisans Tezi, Hasan Kalyoncu Üniversitesi, Türkiye).

Kaya, C. (2019). Demiryolu Hatlarının Emniyetin Sağlanması ile İlgili Risk Analizleri. (Yüksek Lisans Tezi, Sakarya Üniversitesi, Türkiye).

Koçak, Y. (2014). Demiryolu Emniyet Yönetim Sisteminin Risk Analiz Yöntemleri. (Yüksek Lisans Tezi, İstanbul Üniversitesi, Türkiye).

Lafçi, Ö. \& Öztekin, A., (2020). Risk assessment of sea rescue activities on search/rescue ships using L type matrix method. COMU J. Mar. Sci. Fish, 3(2): 66-78. DOI: 10.46384/jmsf.746822.

Railway Applications-Track-Track Geometry Quality, Part 5 (2017). Geometric quality levels - Plain line, switches and crossings, EN 13848-5:2017, European Committee for Standardization.

Sarıgüzel, E. E. (2021). Rayli Sistemlerde Risk Analizi ile Sistem Emniyeti ve Kalitesinin Artırılması. (Yüksek Lisans Tezi, İstanbul Medeniyet Üniversitesi, Türkiye).

Tabak, Ç. (2014). Demiryollarındaki Kaza İstatistikleri Veritabanı, Risk Azaltma Yöntemleri, Alınan Önlemler ve Avrupa'daki Örneklerinin Kıyaslanması. Uzmanlık Tezi, Ulaştırma Denizcilik ve Haberleșme Bakanlığı, Ankara.

TCDD Ar-ge D. (2017). TCDD Emniyet Yönetim Sistemi El Kitabı. Ankara, Tufan Ofset.

TCDD (2012), Kurumsal Faaliyet Raporu.

TCDD (2013). TCDD Hat Bakımı El Kitabı, TCDD Yol Dairesi Başkanlığı, Ankara.

URL 1, https://www.tcddtasimacilik.gov.tr/sayfa/emniyet-politikasi/ Erişim Tarihi: 22.07.2021. 